\title{
ON THE BETA-NUMBER OF FORESTS WITH ISOMORPHIC COMPONENTS
}

\author{
Rikio ICHISHIMA \\ College of Humanities and Sciences, Nihon University, 3-25-40 \\ Sakurajousui Setagaya-ku, Tokyo 156-8550, Japan \\ e-mail: ichishima@msh.biglobe.ne.jp \\ Susana-Clara López \\ Departament de Matemàtiques \\ Universitat Politècnica de Catalunya, BarcelonaTech \\ C/Esteve Terrades 5, 08860 Castelldefels, Spain \\ e-mail: susana.clara.lopez@upc.edu \\ Francesc Antoni Muntaner-Batle \\ AND \\ Akito Oshima \\ Graph Theory and Applications Research Group \\ School of Electrical Engineering and Computer Science \\ Faculty of Engineering and Built Environment \\ The University of Newcastle, NSW 2308 Australia \\ e-mail: famb1es@yahoo.es \\ akitoism@yahoo.co.jp
}

\begin{abstract}
The beta-number, $\beta(G)$, of a graph $G$ is defined to be either the smallest positive integer $n$ for which there exists an injective function $f: V(G) \rightarrow$ $\{0,1, \ldots, n\}$ such that each $u v \in E(G)$ is labeled $|f(u)-f(v)|$ and the resulting set of edge labels is $\{c, c+1, \ldots, c+|E(G)|-1\}$ for some positive integer $c$ or $+\infty$ if there exists no such integer $n$. If $c=1$, then the resulting beta-number is called the strong beta-number of $G$ and is denoted by $\beta_{s}(G)$. In this paper, we show that if $G$ is a bipartite graph and $m$ is odd, then $\beta(m G) \leq m \beta(G)+m-1$. This leads us to conclude that $\beta(m G)=$ $m|V(G)|-1$ if $G$ has the additional property that $G$ is a graceful nontrivial
\end{abstract}


tree. In addition to these, we examine the (strong) beta-number of forests whose components are isomorphic to either paths or stars.

Keywords: beta-number, strong beta-number, graceful labeling, Skolem sequence, hooked Skolem sequence.

2010 Mathematics Subject Classification: Primary: 05C78; Secondary: $05 \mathrm{C} 05$.

\section{REFERENCES}

[1] B.D. Acharya and S.M. Hegde, Strongly indexable graphs, Discrete Math. 93 (1991) 123-129. doi:10.1016/0012-365X(91)90248-Z

[2] R. Cattell, Graceful labellings of paths, Discrete Math. 307 (2007) 3161-3176. doi:10.1016/j.disc.2007.03.046

[3] G. Chartrand and L. Lesniak, Graphs \& Digraphs (Wadsworth \& Brook/Cole Advanced Books and Software, Monterey, Calif., 1986).

[4] A.R. Eckler, Construction of missile guidance codes resistant to random interference, Bell Syst. Tech. J. 39 (1960) 937-994. doi:10.1002/j.1538-7305.1960.tb03950.x

[5] H. Enomoto, A. Lladó, T. Nakamigawa and G. Ringel, Super edge-magic graphs, SUT J. Math. 34 (1998) 105-109.

[6] R.M. Figueroa-Centeno, R. Ichishima, F.A. Muntaner-Batle and M. Rius-Font, Labeling generating matrices, J. Combin. Math. Combin. Comput. 67 (2008) 189-216.

[7] J.A. Gallian, A dynamic survey of graph labeling, Electron. J. Combin. 19 (2016) \#DS6.

[8] S.W. Golomb, How to number a graph, in: Graph Theory and Computing, R.C. Read, Ed. (Academic Press, New York, 1972) 23-37.

[9] R. Ichishima, F.A. Muntaner-Batle and A. Oshima, The measurements of closeness to graceful graphs, Australas. J. Combin. 63 (2015) 197-210.

[10] E.S. O'Keefe, Verification of a conjecture of Th. Skolem, Math. Scand. 9 (1961) $80-82$. doi:10.7146/math.scand.a-10624

[11] S.C. López and F.A. Muntaner-Batle, Langford sequences and a product of digraphs, European J. Combin. 53 (2016) 86-95.

doi:10.1016/j.ejc.2015.11.004

[12] S.C. López, F.A. Muntaner-Batle and M. Rius-Font, Labeling constructions using digraphs products, Discrete Appl. Math. 161 (2013) 3005-3016. doi:10.1016/j.dam.2013.06.006 
[13] A. Rosa, On certain valuations of the vertices of a graph, in: Theory of Graphs (Internat. Symposium, Rome, July 1966), (Gordon and Breach, N.Y. and Dunod, Paris, 1967) 349-355.

[14] A. Rosa, Labeling snakes, Ars Combin. 3 (1977) 67-73.

[15] A. Rosa and J. Širáň, Bipartite labelings of trees and the gracesize, J. Graph Theory 19 (1995) 201-215. doi:10.1002/jgt.3190190207

[16] N. Shalaby, Skolem sequences, in: Handbook of Combinatorial Designs, Second Edition, C.J. Colbourn and J.H. Dinitz (Eds.), Discrete Mathematics and its Applications (Chapman \& Hall/CRC, Boca Raton, FL, 2007) 612-617.

[17] T. Skolem, On certain distribution of integers into pairs with given differences, Math. Scand. 5 (1957) 57-68.

doi:10.7146/math.scand.a-10490

Received 27 July 2016

Revised 30 January 2017

Accepted 30 January 2017 